\title{
Pulmonary arterial medial smooth muscle thickness in sudden infant death syndrome: an analysis of subsets of 73 cases
}

\author{
Henry F. Krous • Elisabeth Haas • \\ Catherine F. Hampton - Amy E. Chadwick • \\ Christina Stanley $\cdot$ Claire Langston
}

Accepted: 13 October 2009/Published online: 28 November 2009

(C) The Author(s) 2009. This article is published with open access at Springerlink.com

\begin{abstract}
Previous studies addressing pulmonary artery morphology have compared cases of sudden infant death syndrome (SIDS) to controls but none have compared demographic profiles, exposure to potentially hypoxic risk factors and other pathologic variables in SIDS cases grouped according to pulmonary artery medial smooth muscle thickness. Aims: To compare the relative medial thickness (RMT) in alveolar wall arteries (AW) in SIDS cases with that in age-matched controls and 2. Compare demographic, clinical, and pathologic characteristics among three subsets of SIDS cases based upon alveolar wall (AW) RMT. Retrospective morphometric planimetry of all muscularized arteries in standardized right apical lung sections in 73 SIDS cases divided into three groups based on increasing AW RMT as well as 19 controls age-matched to 19 of the SIDS cases. SIDS and age-matched control cases did not differ with respect to AW RMT or other demographic variables.
\end{abstract}

H. F. Krous $(\bowtie) \cdot$ E. Haas - A. E. Chadwick

Department of Pathology, Rady Children's Hospital-San Diego, 3020 Children's Way, MC5007, San Diego, CA 92123, USA

e-mail: hkrous@rchsd.org

\section{H. F. Krous}

Departments of Pathology and Pediatrics, University of California, San Diego School of Medicine,

La Jolla, CA, USA

C. Stanley

Office of the Medical Examiner, County of San Diego,

San Diego, CA, USA

C. Langston

Department of Pathology, Texas Children's Hospital and Baylor

College of Medicine, Houston, TX, USA

C. F. Hampton

Cook Children's, Keller, TX, USA
The SIDS group with the thickest AW RMT had significantly more males and premature birth than the other groups, but the groups did not differ for known clinical risk factors that would potentially expose them to hypoxia. Pathologic variables, including pulmonary inflammation, gastric aspiration, intra-alveolar siderophages, cardiac valve circumferences, and heart and liver weights, were not different between groups. Age was not significantly correlated with RMT of alveolar wall and pre-acinar arteries but was significant at $p=.018$ for small intra-acinar arteries. The groups were different for RMT of small pre-acinar and intra-acinar arteries, which increased with increasing AW RMT. Statistical differences should not necessarily be equated with clinical importance, however future research incorporating more quantified historical data is recommended.

Keywords SIDS - Pulmonary artery - ALTE . Morphometry $\cdot$ Medial smooth muscle

\section{Introduction}

Sudden infant death syndrome (SIDS) is defined as "the sudden and unexpected death of an infant under 1 year of age, with onset of the lethal episode apparently occurring during sleep, that remains unexplained after a thorough investigation including performance of a complete autopsy, and review of the circumstances of death and the clinical history [1].

Prior to the early 1980 s, the proposal that recurrent and/ or prolonged apnea was an important risk factor for SIDS [2-6] stimulated numerous pathology studies which evaluated pulmonary artery medial smooth muscle in SIDS, with conflicting results [7-14]. In our prior study on this topic in which standardized approaches were used in death 
scene investigation and autopsy examination, we found that, when adjusted for age, the relative medial thickness (RMT) of the small intra-acinar (SIA) arteries was significantly greater in controls compared to SIDS cases; conversely, the RMT of the preacinar (PA) and alveolar wall (AW) arteries, as well as peripheral medial smooth muscle extension, did not differ between the groups. We therefore concluded that SIDS is an acute event not preceded by recurrent or prolonged apnea and hypoxia [15].

All of the previous studies addressing pulmonary artery morphology in SIDS have compared the findings in these cases to control cases; none exclusively evaluated pulmonary artery medial smooth muscle thickness in subsets of SIDS cases. With this in mind, we hypothesized that the groups of SIDS cases with the thickest pulmonary artery medias would differ from those with the thinnest medias with respect to clinical or pathological variables that suggest a prior history of hypoxia/hypoxemia. Therefore, the aims of this study are to compare 1 . The mean relative medial thickness of the alveolar wall arteries in SIDS and age-matched controls and 2. Demographic, clinical, and pathologic characteristics among subsets of SIDS cases grouped by the magnitude of pulmonary artery medial smooth muscle thickness.

\section{Methods}

Rady Children's Hospital and Health Center Institutional Review Board (IRB) approved this study.

Seventy-three SIDS cases fulfilling the criteria of the San Diego definition [1] as well as 19 controls age-matched to 19 of the 73 SIDS cases, all of which had available standardized pulmonary tissue blocks from the apex of the right upper lobe were the subjects of this analysis. Ninety-five percent (18/19) of the age-matched SIDS and control pairs were matched within 5 days of each other and the oldest control case (243 days) was matched within 9 days of the oldest SIDS case (252 days). All of these cases had been accessioned by the Office of the Chief Medical Examiner of San Diego County (ME), California between 1991 and 2000. To avoid the potential confounding effect of neonatal age on relative medial thickness (RMT) accounted for by smooth muscle, infants $\leq 28$ days of age were excluded. Also infants with congenital heart disease and infants whose gestational age at birth was $\leq 30$ weeks were excluded.

Clinical, death scene and postmortem variables were entered into the San Diego SIDS Research Project database that contains selected information from the records of over 500 cases of infant death due to SIDS, accidents, inflicted injuries and other natural causes. The information was extracted from the ME investigative and autopsy reports and two standardized data protocols comprised of checklists regarding the death scene investigation and postmortem examination. Trained, experienced investigators from the ME obtained this information within $30 \mathrm{~h}$ of an infant's death. In 1989, a California statute mandated use of standardized scene investigation and postmortem examination protocols developed by a multidisciplinary expert committee for cases of sudden, unexpected infant death. The records were searched for information that might affect the amount of pulmonary artery smooth muscle, such as a history of apparent life-threatening events (ALTEs).

In nearly every SIDS and control case, hematoxylin and eosin stained histologic sections were also available from every lobe of both lungs. These particular sections were scored semiquantitatively (HFK) for the following variables: pulmonary hemorrhage, interstitial pneumonitis, aspiration of gastric contents, and lymphoid aggregates. The methods by which the semiquantitative assessment of the severity of these changes was undertaken have been published previously [16-21]. Briefly, the scale for these variables was: $0=$ absent; $1=$ mild, focal; $2=$ moderate, focal; $3=$ severe, focal; and $4=$ severe, diffuse.

Sudden infant death syndrome cases were then divided into three groups based upon the relative medial thickness (RMT) of alveolar wall arteries (AW): Group 1, RMT $<1 \mu \mathrm{m}$; Group 2, $1<2 \mu \mathrm{m}$; and Group 3, $>2 \mu \mathrm{m}$. The groups were then compared for age, gender, prematurity, ethnicity, pre and postnatal exposure to cigarette smoking, history of ALTEs, symptoms of upper respiratory illness (URI) within $48 \mathrm{~h}$ of death, if ever breast-fed as well as face and body position when found lifeless. The pathologic variables included percent of expected weights for height of lungs, heart and liver; expected circumferences of pulmonary and tricuspid valves, pulmonary siderophage counts, and RMT in pre-acinar arteries (PA), and intraacinar arteries accompanying small airways (SIA).

\section{Morphometric analyses}

The methods used in this analysis are identical to those published in our previous study [15]. A single standardized block of non-perfused lung tissue was taken prospectively from the apex of the right upper lobe from each case. Lung perfusion was not performed since other investigators have described a method that accurately measures medial area in uninflated lung; further, these investigators also note that perfusion can cause the pulmonary arteries to sometimes dilate excessively and unpredictably and that changes in the intima may affect the distensibility of an artery [22-25].

The tissue was embedded in paraffin, and histologic sections were cut at $4 \mu$ and stained with Movat 
pentachrome stain to facilitate identification of arterial elastic laminae and medial muscle. Smooth muscle RMT was evaluated according to methods reported by Fernie and Lamb [22-25]. C.W.F. performed all of the measurements for all of the cases. Three measurements, the area within the external elastic lamina (EA), the area within the internal elastic lamina (IA), and the length of the internal elastic lamina (IL), were made using a computer-assisted digitizing system with Bioquant software (Bioquant, Nashville, TN). Images were obtained from a microscope with an attached video camera. Several calculations were made from these measurements. Medial area (MA) was calculated by subtracting the area inside the internal elastic lamina (IA) from the area included inside the external elastic lamina (EA). The radius of the lumen (IR) was calculated by the equation IR $=\mathrm{IL} / 2 \pi$, where IL is the length of the internal elastic lamina. The medial thickness (MT) was calculated by the equation $M T=-I R+$ $\sqrt{I R^{2}+M A / \pi}$. The relative medial thickness (RMT) was calculated by dividing the medial thickness (MT) by the external radius (ER). The external radius (ER) is the sum of the internal radius (IR) plus the medial thickness (MT).

All arteries in cross-section or near cross-section in each Movat stained section were assessed. Partially muscularized vessels were not measured. The measured arteries were grouped according to their locations as preacinar arteries (PA), those that accompany membranous bronchioles or small bronchi; small intra-acinar arteries (SIA), those which accompany terminal and respiratory bronchioles; and alveolar wall arteries (AW). The number of arteries examined per case ranged from 1 to 12 for preacinar, 4 to 13 for small intra-acinar arteries, and 0 to 6 for alveolar wall arteries. The measured and calculated values for each artery were determined three times and their means were used for the present analyses. The RMT mean values were calculated for PA, SIA, and AW arteries for each case. Finally, SIDS group means were calculated for the three artery types. The number of muscularized AW arteries in each of the sections was determined to compare the degree of peripheral extension of medial smooth muscle in SIDS. The vessel diameters were calculated using the external radius.

\section{Statistical analysis}

Chi-square tests and Fisher's exact tests were used with categorical variables. For continuous variables, which included age, expected weights for height of heart, lung and liver; siderophages, small intra-acinar, pre-acinar, and alveolar wall artery relative medial thickness (RMT), the three groups were compared using ANOVA. Pearson correlation coefficient was calculated for age and small intra-acinar, preacinar, and alveolar wall artery RMT. A $p$ value $<.05$ was considered statistically significant. Analyses were done using SPSS version 11.5.

\section{Results}

The relative medial thicknesses of the alveolar wall arteries were not significantly different between 19 SIDS cases and 19 age-matched control cases selected from our original study (SIDS $103.79 \pm 61.2$ days; controls $103.79 \pm 60.8$ days; $p=1.00$ ) [15]. Also, there were no significant differences between the two groups for all other considered variables.

The three SIDS groups were significantly different with respect to male gender $(p=.047)$ and rate of premature birth $<37$ weeks gestation ( $p=.036$; Table 1$)$. Compared to the SIDS group with the thinnest pulmonary alveolar wall arteries, the SIDS group with the thickest pulmonary arteries had a higher percent of males (74 vs. 40\%) and a lower percent of premature births (10 vs. $43 \%$ ). The three SIDS groups were not statistically different for all other considered demographic characteristics, selected pulmonary abnormalities, cardiac valve circumferences, or heart, liver, and lung expected weights (Tables 1, 2, 3, 4, 5).

Conversely, the groups were different for RMT of small pre-acinar and intra-acinar arteries, which increased with increasing AW RMT.

Age was not significantly correlated with the RMT of the alveolar wall and pre-acinar arteries but was significant at $p=.018$ for small intra-acinar arteries.

\section{Discussion}

Pulmonary arteries from the hilum to nonmuscularized vessels in the periphery undergo remodeling in response to hypoxic exposure. Elegantly described by Stenmark et al. [26] the magnitude of the changes are dependent upon the species, gender, and stage of lung development at the time of hypoxic exposure. Muscularization of normally nonmuscularized peripheral vessels is the first cellular response to hypoxia and is a result of an increase in size and number of mural cells forming a media and adventitia. Also migration of interstitial fibroblasts and extravasation of inflammatory and mesenchymal precursor cells into the vessel wall have been proposed as factors contributing to formation and peripheral extension of medial smooth muscle. These cellular and structural changes are driven by release of endothelial vasoconstrictors, growth factors, matrix proteins, and adhesion molecules [26]. In a recent study, hypoxia upregulated stromal cell-derived factor-1 (SDF-1), VEGF, growth-related oncogene protein-alpha (GRO-alpha), C5, ICAM-1, osteopontin (OPN), and 
Table 1 Demographic and clinical characteristics of the SIDS groups defined by their alveolar wall artery relative medial thickness
${ }^{a}$ Acute life-threatening event

${ }^{\mathrm{b}}$ Upper respiratory infection

\begin{tabular}{|c|c|c|c|c|}
\hline $\begin{array}{l}\text { Group, } n \text { of cases } \\
\text { Alveolar wall artery relative } \\
\text { medial thickness, } \mu \mathrm{m}\end{array}$ & $\begin{array}{l}1(n=15) \\
<1\end{array}$ & $\begin{array}{l}2(n=23) \\
1<2\end{array}$ & $\begin{array}{l}3(n=35) \\
\geq 2\end{array}$ & $p$ value \\
\hline Age, mean (SD), days & $120(67)$ & $106(54)$ & $94(43)$ & NS \\
\hline Range & $44-280$ & $31-269$ & $39-252$ & \\
\hline Male gender & $6(40 \%)$ & $12(52 \%)$ & $26(74 \%)$ & .047 \\
\hline \multicolumn{5}{|l|}{ Ethnicity } \\
\hline White & $6(40 \%)$ & $11(48 \%)$ & $18(51 \%)$ & NS \\
\hline Hispanic & $1(7 \%)$ & $6(26 \%)$ & $10(29 \%)$ & \\
\hline Black & $4(27 \%)$ & $5(22 \%)$ & $4(11 \%)$ & \\
\hline All Others & $4(27 \%)$ & $1(4 \%)$ & $3(9 \%)$ & \\
\hline Prematurity ( $<37$ weeks) & $\begin{array}{l}n=14 \\
6(43 \%)\end{array}$ & $\begin{array}{l}n=21 \\
6(29 \%)\end{array}$ & $\begin{array}{l}n=31 \\
3(10 \%)\end{array}$ & .036 \\
\hline Pre- or post-natal exposure to tobacco smoke & $\begin{array}{l}n=10 \\
4(40 \%)\end{array}$ & $\begin{array}{l}n=18 \\
6(33 \%)\end{array}$ & $\begin{array}{l}n=18 \\
7(39 \%)\end{array}$ & NS \\
\hline Previous $\mathrm{ALTE}^{\mathrm{a}}$ & $\begin{array}{l}n=13 \\
2(15 \%)\end{array}$ & $\begin{array}{l}n=17 \\
1(6 \%)\end{array}$ & $\begin{array}{l}n=17 \\
2(12 \%)\end{array}$ & NS \\
\hline Symptoms of URI within $48 \mathrm{~h}$ of death ${ }^{\mathrm{b}}$ & $\begin{array}{l}n=15 \\
5(33 \%)\end{array}$ & $\begin{array}{l}n=23 \\
8(35 \%)\end{array}$ & $\begin{array}{l}n=33 \\
16(48 \%)\end{array}$ & NS \\
\hline Bedsharing & $4(27 \%)$ & $5(22 \%)$ & $10(29 \%)$ & NS \\
\hline Placed prone or side & $\begin{array}{l}n=13 \\
8(62 \%)\end{array}$ & $\begin{array}{l}n=10 \\
8(80 \%)\end{array}$ & $\begin{array}{l}n=23 \\
22(96 \%)\end{array}$ & .034 \\
\hline Found face down & $\begin{array}{l}n=8 \\
3(38 \%)\end{array}$ & $\begin{array}{l}n=19 \\
7(37 \%)\end{array}$ & $\begin{array}{l}n=21 \\
8(38 \%)\end{array}$ & NS \\
\hline Body found prone & $\begin{array}{l}n=14 \\
8(57 \%)\end{array}$ & $\begin{array}{l}n=21 \\
15(71 \%)\end{array}$ & $\begin{array}{l}n=29 \\
25(86 \%)\end{array}$ & NS \\
\hline $\begin{array}{l}\text { No. of hypoxia risk factors: } \\
\text { mean (SD) range }\end{array}$ & $\begin{array}{l}2.13(.92) \\
0-4\end{array}$ & $\begin{array}{l}2.17(1.11) \\
0-4\end{array}$ & $\begin{array}{l}2.57(1.04) \\
0-4\end{array}$ & NS \\
\hline
\end{tabular}

transforming growth factor-beta (TGF-beta) in WistarKyoto rats leading to progressive accumulation of monocytes and dendritic cells into the pulmonary arterial walls [27]. Additionally, adhesion molecule upregulation as well as monocyte/fibrocyte growth and differentiation suggest that a proinflammatory microenvironment capable of promoting recruitment, retention, and differentiation of circulating monocytic cell populations contributes to vascular remodeling. Large pulmonary arteries experience increased thickening of the media and adventitia in response to hypoxia resulting in increased wall stiffness that imposes a $30-40 \%$ increase in the load to the right ventricle with subsequent right ventricular hypertrophy and loss of stroke volume and pulmonary blood flow [26].

In our study, the relative medial thickness of the alveolar wall arteries did not significantly differ between SIDS cases and age-matched controls, confirming our previous finding [15]. The conflicting results of other studies [8, 9, $12,14]$ are likely a result of differing analytical methods and the lack of standardized SIDS definitions, case investigations, and autopsies. Given hypoxia-induced smooth muscle proliferation in pulmonary arteries requires several days, the duration and/or severity of hypoxic exposure relative to the time of death must also be considered. Thus, arterial smooth muscle proliferation may not be apparent after hypoxic episodes occurring shortly before death or long after remote or in utero hypoxia. Nevertheless, the absence of a difference in alveolar wall artery smooth muscle between our SIDS and control cases in our study remains intriguing given literature suggesting that at least some SIDS cases have experienced hypoxia/hypoxemia prior to their deaths [28-34]. Elevated VEGF levels and being found with the face straight down into the sleep surface are consistent with acute hypoxia shortly prior to death, but do not confirm either chronic or recurrent prolonged apnea causing hypoxia.

Compared to the SIDS group with the thinnest pulmonary alveolar wall arteries, those with the thickest arteries included a significantly higher percent of males (74 vs. $40 \%$ ) and a lower percent of premature births (10 vs. $43 \%$; Table 1). The percentages of cases that were male or prematurely born in the SIDS group with alveolar wall artery thicknesses between the groups with the thinnest and thickest medias were intermediate. SIDS has long been 
Table 2 Histopathologic findings in SIDS subsets as a function of the alveolar wall artery mean medial thickness a One case is missing pulmonary hemorrhage score

b Grade of histological severity: $0=$ absent, $1=$ mild,

$2=$ moderate, $3=$ severe and focal, $4=$ severe and multifocal

\begin{tabular}{|c|c|c|c|c|c|}
\hline \multicolumn{2}{|c|}{$\begin{array}{l}\text { Group, } n \text { of cases } \\
\text { Alveolar wall arteries medical thickness, }(\mu \mathrm{m})\end{array}$} & \multirow[t]{2}{*}{$\begin{array}{l}1,(n=15) \\
<1\end{array}$} & \multirow[t]{2}{*}{$\begin{array}{l}2,(n=23) \\
1<2\end{array}$} & \multirow[t]{2}{*}{$\begin{array}{l}3,(n=35)^{\mathrm{a}} \\
\geq 2\end{array}$} & \multirow[t]{2}{*}{$p$ value } \\
\hline & $\begin{array}{l}\text { Histologic } \\
\text { grade }^{\text {b }}\end{array}$ & & & & \\
\hline \multirow[t]{5}{*}{ Pulmonary hemorrhage [21] } & 0 & $3(20 \%)$ & $8(35 \%)$ & $12(35 \%)$ & \multirow[t]{5}{*}{ NS } \\
\hline & 1 & $5(33 \%)$ & $8(35 \%)$ & $11(32 \%)$ & \\
\hline & 2 & $4(27 \%)$ & $5(22 \%)$ & $5(15 \%)$ & \\
\hline & 3 & $3(20 \%)$ & $2(9 \%)$ & $4(12 \%)$ & \\
\hline & 4 & & & $2(6 \%)$ & \\
\hline \multirow[t]{5}{*}{ Interstitial pneumonitis [17] } & 0 & $5(33 \%)$ & $6(26 \%)$ & $10(29 \%)$ & \multirow[t]{5}{*}{ NS } \\
\hline & 1 & $9(60 \%)$ & $11(48 \%)$ & $20(57 \%)$ & \\
\hline & 2 & $1(7 \%)$ & $6(26 \%)$ & $5(14 \%)$ & \\
\hline & 3 & & & & \\
\hline & 4 & & & & \\
\hline \multirow[t]{5}{*}{ Gastric aspiration [19] } & 0 & $12(80 \%)$ & $20(87 \%)$ & $28(80 \%)$ & \multirow[t]{5}{*}{ NS } \\
\hline & 1 & $3(20 \%)$ & $1(4 \%)$ & $1(3 \%)$ & \\
\hline & 2 & & $2(9 \%)$ & $2(6 \%)$ & \\
\hline & 3 & & & $4(11 \%)$ & \\
\hline & 4 & & & & \\
\hline \multirow[t]{5}{*}{ Lymphoid aggregates [17] } & 0 & $6(40 \%)$ & $7(30 \%)$ & $10(29 \%)$ & \multirow[t]{5}{*}{ NS } \\
\hline & 1 & $2(13 \%)$ & $9(39 \%)$ & $15(43 \%)$ & \\
\hline & 2 & $4(27 \%)$ & $5(22 \%)$ & $5(14 \%)$ & \\
\hline & 3 & $3(20 \%)$ & $1(4 \%)$ & $4(11 \%)$ & \\
\hline & 4 & & $1(4 \%)$ & $1(3 \%)$ & \\
\hline
\end{tabular}

Table 3 Mean number of pulmonary siderophages as a function of the alveolar wall artery mean relative medial thickness

\begin{tabular}{llll}
\hline $\begin{array}{l}\text { Group, } n \text { of cases } \\
\text { Alveolar wall artery medial thickness, }(\mu \mathrm{m})\end{array}$ & $\begin{array}{l}1,(n=15) \\
<1\end{array}$ & $\begin{array}{l}2,(n=23) \\
1<2\end{array}$ & $\begin{array}{l}3,(n=35) \\
\geq 2\end{array}$ \\
\hline $\begin{array}{l}\text { Number of cases with lung sections stained for } \\
\text { iron-laden macrophages (siderophages) }\end{array}$ & 15 & 14 & 23 \\
$\begin{array}{l}\text { Mean (SD) } \\
\text { Range }\end{array}$ & $211(487)$ & $15(13)$ & $72(225)$ \\
\end{tabular}

${ }^{a}$ Mean number of pulmonary intra-alveolar siderophages/20 contiguous high power fields $(\times 400)[18]$

known to disproportionately affect males, $[35,36]$ perhaps as a result of significantly lower serotonin receptor binding density in the raphe obscurus compared with females [37]. Previous studies have not evaluated pulmonary artery thickness as a function of gender. Similarly, premature birth has long been recognized as a SIDS risk factor [35, 36].

Rates of risk factors that could specifically expose the SIDS cases to hypoxia including pre- and/or post-natal tobacco smoke exposure, previous ALTE, URI within $48 \mathrm{~h}$ of death, bedsharing, placed prone or side, found face down, and body found prone, whether individually or collectively, were not significantly different between SIDS subsets (Table 1). Furthermore, the SIDS groups did not differ from one another with respect to age and ethnicity.
Despite differences in the relative medial thickness in alveolar wall arteries between groups, the lack of observed differences in right heart valve circumference and expected weights of the heart and liver suggest that the pulmonary artery pathology was either insufficiently severe or the interval(s) were too short to produce differences in the severity of pulmonary hemorrhage (Table 2) or evidence of right heart dilation, myocardial hypertrophy or cardiac failure. Absence of significant differences in mean pulmonary intra-alveolar siderophage counts argues against prior hemorrhage to account for the pulmonary arterial differences (Table 3).

For all groups, age was not significantly correlated with the relative medial thickness of the alveolar wall and preacinar arteries but was inversely correlated for small intra- 
Table 4 Observed cardiac valve circumference percentile as a function of alveolar wall artery mean relative medial thickness

\author{
a Tricuspid valve \\ circumference unavailable in \\ one case, which has been \\ excluded
}

\begin{tabular}{lllll}
\hline $\begin{array}{l}\text { Group, } n \text { of cases } \\
\text { Alveolar wall artery RMT, }(\mu \mathrm{m})\end{array}$ & $\begin{array}{l}1,(n=15) \\
\begin{array}{l}\text { Number of cases with measured } \\
\text { valve circumference }\end{array}\end{array}$ & $\begin{array}{l}2,(n=23) \\
1<2\end{array}$ & $\begin{array}{l}3,(n=35) \\
\geq 2 \\
28^{\mathrm{a}}\end{array}$ & $p$ value \\
\hline $\begin{array}{l}\text { Pulmonary valve } \\
<100 \%\end{array}$ & 13 & & \\
$100-125 \%$ & $2(22 \%)$ & $6(46 \%)$ & $10(36 \%)$ & NS \\
$>125 \%$ & $5(56 \%)$ & $5(38 \%)$ & $17(61 \%)$ & \\
Tricuspid valve & $2(22 \%)$ & $2(15 \%)$ & $1(4 \%)$ & \\
$<100 \%$ & & & & \\
$100-125 \%$ & $8(89 \%)$ & $8(62 \%)$ & $12(44 \%)$ & $\mathrm{NS}$ \\
$>125 \%$ & $1(11 \%)$ & $2(15 \%)$ & $12(44 \%)$ & \\
\hline
\end{tabular}

Table 5 Expected organ weight percentile as a function of alveolar wall artery mean relative medial thickness

\begin{tabular}{|c|c|c|c|c|}
\hline $\begin{array}{l}\text { Group, } n \text { of cases } \\
\text { Alveolar wall artery } \\
\text { RMT, }(\mu \mathrm{m})\end{array}$ & $\begin{array}{l}1,(n=15) \\
<1\end{array}$ & $\begin{array}{l}2,(n=23) \\
1<2\end{array}$ & $\begin{array}{l}3,(n=35)^{\mathrm{a}} \\
\geq 2\end{array}$ & $p$ value \\
\hline \multicolumn{5}{|l|}{ Lungs } \\
\hline$<100 \%$ & $1(7 \%)$ & & & NS \\
\hline $100-150 \%$ & $5(33 \%)$ & $9(39 \%)$ & $11(31 \%)$ & \\
\hline$>150 \%$ & $9(60 \%)$ & $14(61 \%)$ & $24(69 \%)$ & \\
\hline \multicolumn{5}{|l|}{ Heart } \\
\hline$<100 \%$ & $4(27 \%)$ & $2(9 \%)$ & $9(26 \%)$ & NS \\
\hline $100-150 \%$ & $8(53 \%)$ & $20(87 \%)$ & $26(74 \%)$ & \\
\hline$>150 \%$ & $3(20 \%)$ & $1(4 \%)$ & & \\
\hline \multicolumn{5}{|l|}{ Liver } \\
\hline$<100 \%$ & $3(20 \%)$ & $4(17 \%)$ & $2(6 \%)$ & NS \\
\hline $100-150 \%$ & $9(60 \%)$ & $16(70 \%)$ & $26(76 \%)$ & \\
\hline$>150 \%$ & $3(20 \%)$ & $3(13 \%)$ & $6(18 \%)$ & \\
\hline
\end{tabular}

${ }^{a}$ Liver weight unavailable in one case, which has been excluded

acinar arteries $(p=.018$; data available upon request). This is to be expected as pulmonary arterial medial smooth muscle normally declines with increasing postnatal age (Pearson correlation coefficient for age by SIA -.277) and suggests that medial smooth muscle recedes more quickly in the alveolar wall and pre-acinar arteries. This smooth muscle proliferation can also occur in utero in late gestation as a reactive change. In the human fetus, pulmonary arteries develop a relatively thick muscle wall that normally diminishes rapidly after birth [38]. In piglets exposed to hypoxia from birth, the normal reduction in arterial muscularity is not only arrested, but reversed as exposure time to hypoxia is lengthened [39]. Animals that are fully adapted to extra-uterine life and then exposed to hypoxia initially at age 14 days show an increase in muscularity that is characterized by an increase in wall thickness and muscular extension into smaller and more peripheral arteries than is normal. In this regard, it is noteworthy that
Table 6 Intra-acinar and pre-acinar artery mean relative medial thicknesses as a function of alveolar wall artery mean relative medical thickness

\begin{tabular}{lllll}
\hline $\begin{array}{l}\text { Group, } n \text { of cases } \\
\text { Alveolar wall RMT, }(\mu \mathrm{m})\end{array} \begin{array}{llll}1, n=15 \\
<1\end{array}$ & $\begin{array}{l}2, n=23 \\
1<2\end{array}$ & $\begin{array}{l}3, n=35 \\
\geq 2^{\mathrm{a}}\end{array}$ & $p$ value \\
\hline $\begin{array}{l}\text { Intra-acinar arteries RMT, }(\mu \mathrm{m}) \\
.18(.03)\end{array}$ & $.46(.12)$ & $.56(.13)$ & .000 \\
Mean (SD) & $.11-.21$ & $.26-.85$ & $.34-.92$ & \\
Range & $.2(.06)$ & $.24(.08)$ & $.34(.15)$ & .000 \\
Pre-acinar arteries RMT, $(\mu \mathrm{m})$ & $.13-.34$ & $.14-.42$ & $.1-.86$ & \\
Mean (SD) & & & & \\
Range &
\end{tabular}

${ }^{a}$ Pre-acinar artery measurement is unavailable in one case, which has been excluded

the group in our study with the least pulmonary artery muscle has the highest percent of births occurring at $<37$ weeks gestation.

Table 6 shows increasing RMT of pre-acinar and intraacinar arteries with increasing RMT of alveolar wall arteries. This suggests that increasing muscularization is seen in all categories of vessels with a stimulus sufficient to produce it in alveolar wall arteries and that any of the classes of arteries could have been used as the basis to group the cases with the same outcome.

Our study is limited by the relatively small number of cases in each of the groups, nevertheless statistical analyses were able to demonstrate significant differences between subsets of SIDS cases that are worthy of future research. In addition to a larger number of cases, more complete historical data with quantification of relevant conditions predisposing to hypoxia would enhance our understanding of the morphometric data.

Conversely, our study is strengthened by use of the most current SIDS definition [1], relatively standardized approaches to death scene evaluation and autopsy examination, and performance of the morphometric measurements by the same experienced individual [15]. And, unlike some of the earlier studies, $[9,13,14]$ our investigation 
evaluated all of the available completely muscularized arteries in the histologic sections. We also used a more refined planimetric technique [22-25] that was developed well after the earlier morphometric studies were reported, and stratified the pulmonary arteries according to the accompanying airway, rather than simply on their size, as had been done in several of the previous studies, [7, 9-14] thus allowing comparison of equivalent arteries and artery size and structure, regardless of patient age [11].

In conclusion, the mean relative medical thickness of the alveolar wall arteries did not differ between SIDS and agematched control cases. Conversely, when SIDS cases were divided into groups based on mean relative medial thickness of the alveolar wall arteries, they differed with respect to the percent that were male or born prematurely, but did not differ on rates of risk factors, individually or collectively, that would potentially expose them to hypoxia. Further research aimed at correlating more complete historical data pertaining to possible hypoxia in SIDS with pulmonary morphometry are recommended as is correlation of pulmonary artery morphometric findings with other subtle abnormalities in SIDS, such as medullary serotonergic system abnormalities, [40] pulmonary intra-alveolar siderophages, [18] and intrathoracic petechiae [16].

\section{Key points}

1. Environmental factors, e.g., prone sleep position or soft sleep surfaces, increase the risk for SIDS probably as a result of asphyxia.

2. Previous studies have compared pulmonary arteriolar medial smooth muscle thickness in SIDS cases and controls and generally shown no differences between groups.

3. In this study demographic variables and pulmonary arteriolar medial smooth muscle thicknesses were not different between SIDS cases and age-matched controls.

4. This study, the first of its kind, found that the SIDS group with the thickest alveolar wall arteries had significantly more males and premature births, but not risk factors or pathologic variables suggesting prior hypoxic exposure, than the other SIDS groups.

5. Statistical differences should not necessarily be equated to clinical importance.

\footnotetext{
Acknowledgments The authors thank the First Candle/SIDS Alliance and the CJ Foundation for SIDS for grant support and the many survivors of SIDS infants for their monetary contributions.
}

Open Access This article is distributed under the terms of the Creative Commons Attribution Noncommercial License which permits any noncommercial use, distribution, and reproduction in any medium, provided the original author(s) and source are credited.

\section{References}

1. Krous HF, Beckwith JB, Byard RW, et al. Sudden infant death syndrome and unclassified sudden infant deaths: a definitional and diagnostic approach. Pediatrics. 2004;114:234-8.

2. Steinschneider A. Prolonged apnea and the sudden infant death syndrome: clinical and laboratory observations. Pediatrics. 1972; 50:646-54.

3. Guntheroth WG. Sudden infant death syndrome (crib death). Am Heart J. 1977;93:784-93.

4. Ariagno RL, Guilleminault C, Korobkin R, Owen-Boeddiker M, Baldwin R. 'Near-miss' for sudden infant death syndrome infants: a clinical problem. Pediatrics. 1983;71:726-30.

5. Brooks JG. Apnea of infancy and sudden infant death syndrome. Am J Dis Child. 1982;136:1012-23.

6. Guilleminault C, Ariagno RL, Forno LS, Nagel L, Baldwin R, Owen M. Obstructive sleep apnea and near miss for SIDS: I. Report of an infant with sudden death. Pediatrics. 1979;63:83743.

7. Naeye RL. Pulmonary arterial abnormalities in the sudden-infantdeath syndrome. N Engl J Med. 1973;289:1167-70.

8. Naeye RL, Whalen P, Ryser M, Fisher R. Cardiac and other abnormalities in the sudden infant death syndrome. Am J Pathol. 1976;82:1-8.

9. Kendeel SR, Ferris JA. Apparent hypoxic changes in pulmonary arterioles and small arteries in infancy. J Clin Pathol. 1977;30: 481-5.

10. Mason JM, Mason LH, Jackson M, Bell JS, Francisco JT, Jennings BR. Letter: pulmonary vessels in SIDS. N Engl J Med. 1975;292:479.

11. Williams A, Vawter G, Reid L. Increased muscularity of the pylmonary circulation in victims of sudden infant death syndrome. Pediatrics. 1979;63:18-23.

12. Weiler G, de Haardt J. Morphometrical investigations into alterations of the wall thickness of small pulmonary arteries after birth and in cases of sudden infant death syndrome (SIDS). Forensic Sci Int. 1983;21:33-42.

13. Valdes-Dapena MA, Gillane MM, Cassady JC, Catherman R, Ross D. Wall thickness of small pulmonary arteries. Its measurement in victims of sudden infant death syndrome. Arch Pathol Lab Med. 1980;104:621-4.

14. Singer DB, Tilley E. Pulmonary arteries and arterioles: normal in the sudden infant death syndrome. In: Harper RM, Hoffman HJ, editors. Sudden infant death syndrome. New York, NY: PMA Publishing Corporation; 1988. p. 101-14.

15. Krous HF, Floyd CW, Nadeau JM, Silva PD, Blackbourne BD, Langston C. Medial smooth muscle thickness in small pulmonary arteries in sudden infant death syndrome revisited. Pediatr Dev Pathol. 2002;5:4.

16. Krous HF, Nadeau JM, Silva PD, Blackbourne BD. Intrathoracic petechiae in sudden infant death syndrome: relationship to face position when found. Pediatr Dev Pathol. 2001;4:160-6.

17. Krous HF, Nadeau JM, Silva PD, Blackbourne BD. A comparison of respiratory symptoms and inflammation in sudden infant death syndrome and in accidental or inflicted infant death. Am J Forensic Med Pathol. 2003;24:1-8.

18. Krous HF, Wixom C, Chadwick AE, Haas EA, Silva PD, Stanley C. Pulmonary intra-alveolar siderophages in SIDS and suffocation: a San Diego SIDS/SUDC research project report. Pediatr Dev Pathol. 2006;9:103-14. 
19. Krous HF, Masoumi H, Haas EA, Chadwick AE, Stanley C, Thach BT. Aspiration of gastric contents in sudden infant death syndrome without cardiopulmonary resuscitation. J Pediatr. 2007;150: 241-6.

20. Krous HF, Chadwick AE, Haas EA, Stanley C. Pulmonary intraalveolar hemorrhage in SIDS and suffocation. J Forensic Leg Med. 2007;14(8):461-70.

21. Krous HF, Haas EA, Masoumi H, Chadwick AE, Stanley C. A comparison of pulmonary intra-alveolar hemorrhage in cases of sudden infant death due to SIDS in a safe sleep environment or to suffocation. Forensic Sci Int. 2007;172:56-62.

22. Fernie JM, Lamb D. Method for maximising measurements of muscular pulmonary arteries. J Clin Pathol. 1985;38:1380-7.

23. Fernie JM, Lamb D. New method for measuring intimal component of pulmonary arteries. J Clin Pathol. 1985;38:1374-9.

24. Fernie JM, McLean A, Lamb D. New method for quantitating the medial component of pulmonary arteries. Factors affecting the measurements. Arch Pathol Lab Med. 1985;109:843-8.

25. Fernie JM, Lamb D. A new method for quantitating the medial component of pulmonary arteries. The measurements. Arch Pathol Lab Med. 1985;109:156-62.

26. Stenmark KR, Fagan KA, Frid MG. Hypoxia-induced pulmonary vascular remodeling: cellular and molecular mechanisms. Circ Res. 2006;99:675-91.

27. Burke DL, Frid MG, Kunrath CL, et al. Sustained hypoxia promotes the development of a pulmonary artery-specific chronic inflammatory microenvironment. Am J Physiol Lung Cell Mol Physiol. 2009;297:L238-50.

28. Carpenter KH, Bonham JR, Worthy E, Variend S. Vitreous humour and cerebrospinal fluid hypoxanthine concentration as a marker of pre-mortem hypoxia in SIDS. J Clin Pathol. 1993;46: $650-3$.

29. Opdal SH, Rognum TO, Vege A, Saugstad OD. Hypoxanthine levels in vitreous humor: a study of influencing factors in sudden infant death syndrome [in process citation]. Pediatr Res. 1998;44: 192-6.
30. Rognum TO, Saugstad OD, Oyasaeter S, Olaisen B. Elevated levels of hypoxanthine in vitreous humor indicate prolonged cerebral hypoxia in victims of sudden infant death syndrome. Pediatrics. 1988;82:615-8.

31. Takashima S, Armstrong D, Becker L, Bryan C. Cerebral hypoperfusion in the sudden infant death syndrome? Brainstem gliosis and vasculature. Ann Neurol. 1978;4:257-62.

32. Cutz E, Perrin DG, Pan J, Haas EA, Krous HF. Pulmonary neuroendocrine cells and neuroepithelial bodies in sudden infant death syndrome: potential markers of airway chemoreceptor dysfunction. Pediatr Dev Pathol. 2007;10:106-16.

33. Oehmichen M, Woetzel F, Meissner C. Hypoxic-ischemic changes in SIDS brains as demonstrated by a reduction in MAP2reactive neurons. Acta Neuropathol. 2009;117(3):267-74.

34. Jones KL, Krous HF, Nadeau J, Blackbourne B, Zielke HR, Gozal D. Vascular endothelial growth factor in the cerebrospinal fluid of infants who died of sudden infant death syndrome: evidence for antecedent hypoxia. Pediatrics. 2003;111:358-63.

35. Beckwith JB. The sudden infant death syndrome. Curr Probl Pediatr. 1973;3:1-36.

36. Hauck FR. Changing epidemiology. In: Byard RW, Krous HF, editors. Sudden infant death syndrome: problems, progress \& possibilities. London: Arnold; 2001. p. 31-57.

37. Paterson DS, Trachtenberg FL, Thompson EG, et al. Multiple serotonergic brainstem abnormalities in sudden infant death syndrome. Jama. 2006;296:2124-32.

38. Hislop A. Developmental biology of the pulmonary circulation. Paediatr Respir Rev. 2005;6:35-43.

39. Haworth SG, Hislop AA. Effect of hypoxia on adaptation of the pulmonary circulation to extra-uterine life in the pig. Cardiovasc Res. 1982;16:293-303.

40. Kinney HC. Abnormalities of the brainstem serotonergic system in the sudden infant death syndrome: a review. Pediatr Dev Pathol. 2005;8:507-24. 